\title{
A Robust Optimization Model to the Day-Ahead Operation of an Electric Vehicle Aggregator Providing Reliable Reserve
}

\author{
Antonio Jiménez-Marín and Juan Pérez-Ruiz *(D) \\ Departamento de Ingeniería Eléctrica, Universidad de Málaga, E-29071 Málaga, Spain; ajm@uma.es \\ * Correspondence: jperez@uma.es
}

Citation: Jiménez-Marín, A.;

Pérez-Ruiz, J. A Robust Optimization Model to the Day-Ahead Operation of an Electric Vehicle Aggregator Providing Reliable Reserve. Energies 2021, 14, 7456. https://doi.org/ $10.3390 /$ en14227456

Academic Editor: Francisco Javier Ruiz-Rodríguez

Received: 18 October 2021

Accepted: 4 November 2021

Published: 9 November 2021

Publisher's Note: MDPI stays neutral with regard to jurisdictional claims in published maps and institutional affiliations.

Copyright: (C) 2021 by the authors Licensee MDPI, Basel, Switzerland. This article is an open access article distributed under the terms and conditions of the Creative Commons Attribution (CC BY) license (https:// creativecommons.org/licenses/by/ $4.0 /)$.

\begin{abstract}
This paper presents a robust optimization model to find out the day-ahead energy and reserve to be scheduled by an electric vehicle (EV) aggregator. Energy can be purchased from, and injected to, the distribution network, while upward and downward reserves can be also provided by the EV aggregator. Although it is an economically driven model, the focus of this work relies on the actual availability of the scheduled reserves in a future real-time. To this end, two main features stand out: on one hand, the uncertainty regarding the EV driven pattern is modeled through a robust approach and, on the other hand, a set of non-anticipativity constraints are included to prevent from unavailable future states. The proposed model is posed as a mixed-integer robust linear problem in which binary variables are used to consider the charging, discharging or idle status of the EV aggregator. Results over a 24-h case study show the capability of the proposed model.
\end{abstract}

Keywords: EV aggregator; energy and reserve schedule; robust optimization; non-anticipativity constraints

\section{Introduction}

Due to environmental concerns, an increasing interest in the deployment of distributed energy resources (DERs) and electric vehicles (EVs) is expected [1]. These new participants in electric systems will be a high number of small users modifying the traditional load curves and, in many cases, able to provide energy to the power system, for instance, through photovoltaic generation or vehicle-to-grid (V2G) capability. In addition, the energy storage capacity of EVs enables them to provide ancillary services [2], regardless of the different operational structures of the reserve markets. However, these new players bring new sources of uncertainty, such as the intermittency in the DERs or the driving patterns and availability of the EVs. Consequently, this changing situation poses new challenges for the optimal operation of future electricity systems from a technical and economic point of view, as well as in the establishment of an adequate regulatory framework. Smart grids and microgrids, energy communities and, in the scope of this paper, aggregators [3], have emerged as concepts or participants to respond to this new reality.

The technical literature includes a wide variety of studies addressing the topic of optimal operation of an EV aggregator and several review papers have been published. In [4], a review of the literature on business models for smart grid services and some pilot projects is provided, while the review paper in [5] addresses several works focusing the multilevel control and management of EVs integrated in a microgrid. Regarding EVs, the work in [6] presents a discussion of different optimization approaches to face the EV charging, and [7] presents the framework, benefits, and challenges of V2G technology. An insight in operational and financial aspects of aggregator's business models is provided in [8], and the potential of a fleet of EVs, managed by an EV aggregator, to provide ancillary services is described in [9]. A thorough analysis of the value of the aggregators in a power system may be found in [10], where the authors conclude that regulators or policy makers should remove barriers to aggregation in those cases in which it creates a fundamental or transitory value. 
Regarding this regulation issue, the work in [11] performs an analysis of the current regulation in European countries and identifies several necessary changes to foster the potential of DERs to provide flexibility. The technical, regulatory and economical drawbacks faced by a fleet of EVs to provide secondary reserve in the German wholesale electricity market are highlighted in [12]. In the same sense, the economic analysis developed in [13] concludes that, under the current regulation in the German market and even ignoring the investment costs, the opportunity costs arising from not immediately charging vehicles at the parking are higher than the revenues from frequency regulation.

The optimal operation of EVs without the provision of ancillary services has been also widely addressed. Some of these works are described next. In [14], the energy charging scheduling problem is solved by means of a generalized Stackelberg game in which the aggregator is the leader and EVs are the followers. The work in [15] presents a deterministic non-linear optimization model to analyze different strategies for the optimal day-ahead operational planning of a microgrid integrating a EV fleet with V2G capacity. In [16], a stochastic robust optimization model in which uncertainties in the day-ahead market prices and in the driving requirements of EVs are modeled through scenarios and confidence bounds, respectively. A robust optimization procedure is presented in [17] to handle the uncertainty associated to the energy market price. The work in [18] proposes a decentralized model to the coordinate operation of a smart distribution network and a set of EV aggregators in which a robust approach is used to handle the uncertainty sources considered: wind generation and wholesale market price. A stochastic programming model to optimize the charging and discharging operation of an EV aggregator participating in the day-ahead energy market is proposed in [19] in which uncertainties, DA market price, and driving requirements are modeled through scenarios. The work in [20] presents a model to optimize the amount of electricity to be purchased in the day-ahead market by a residential aggregator of a fleet of EVs, in which a bilevel problem is proposed to perform a robust formulation of the driving pattern uncertainty. In [21], both the day-ahead and real-time stages are considered to determine the optimal charging and discharging strategy in a multilevel hierarchical approach.

A selection of works addressing the optimal operation of an aggregator able to provide ancillary services is provided next. A sequential optimization procedure is presented in [22], where the day-ahead is based on forecasted values while the real-time stage aims at minimizing deviations from scheduled bids; this work was later adapted in [23] to consider secondary reserves in both directions. The work in [24] proposes a sequential bidding and repairing procedure for an aggregator trading energy and reliable negative reserve in a multi-market environment, but it does not consider vehicle to grid capability. Additionally, including the capacity of providing reserve in the day-ahead market, a sequential threestage strategy is developed in [25] to determine an optimal strategy mutually beneficial for EV owners and the aggregator; this model is reformulated in [26] as a stochastic programming problem. These two works consider both the day-ahead and the real-time stages, and the later stage includes a penalization term for deviations between two stages. A model for the participation of EVs in secondary frequency response through an EV aggregator that takes into account EV user's preferences is presented in [27]. The mixedinteger programming problem proposed in [28] shows the valuable flexibility introduced in a system-wide framework by a large number of EVs providing spinning reserve. A probabilistic model is proposed in [29] to assess the expected profit an EV aggregator may reach by participating in both the energy and regulation markets. The paper in [30] describes a risk-constrained two-stage stochastic programming model for the participation of an EV aggregator in the day-ahead energy and reserve markets in which an hourly probability is set to each scenario in which the EV aggregator has to provide reserve energy. In [31], two models are presented: on one hand, a two-stage stochastic programming model to determine the energy demand and supply bids in the day-ahead market and, on the other hand, a model predictive control intended for the optimal operation of flexible loads in the real-time; this work is extended in [32] to trade energy and reserve in both day- 
ahead and reserve markets. The stochastic model presented in [33] aims at optimizing the operation of an EV aggregator in the day-ahead and reserve markets, taking into account the uncertainty in the driving patterns of EV owners and in market prices. In [34], a sequential procedure based on receding time horizon is proposed to determine the optimal charging and reserve provided by the EVs located in a car park; in this paper, a robust approach is used to consider the uncertainty of energy and reserve prices and an ageing model is presented to estimate the EV battery degradation. A multi-stage approach is presented in [35] to provide voltage support to the distribution network. The work in [36] presents a long-term planning model to compare two investment alternatives to provide ancillary services and dynamic support services: EV aggregators versus energy storage systems. The study in [37] proposes a scenario-based procedure in which a mixed-integer non-linear programming problem, solved by a gravitational search algorithm, is formulated to maximize the spinning reserve an aggregator can provide to the system. Finally, some other papers propose a bilevel formulation to face the problem of the optimal operation of an aggregator providing ancillary services. The study in [38] proposes a bilevel model in which the optimal operation of an aggregator controlling a set of flexible loads is included in the upper level, while the clearing of the day-ahead energy and reserve markets is in the lower-level problem. The work in [39] proposes a bilevel model to formulate the day-ahead optimal operation of an aggregator, in the upper level, while the set of problems faced by EV owners is included as lower level problems; in this paper, only upward reserve is considered, as spinning reserve, and the feasibility of the solution is not ensured in the real-time.

However, previously discussed models may result in a day-ahead scheduling solution that might be infeasible in the real-time, depending on whether reserves committed in the day-ahead are deployed or not in the real-time. Some of these models, in accordance with the multi-stage structure of most markets, handle this eventual situation by means of a set of penalty costs.

In this work, we propose a mixed-integer linear robust optimization model to determine the energy and reserve to be committed by an aggregator of EVs in the day-ahead stage. The uncertainty related to the driving pattern of EV owners is included in the model through a robust approach [40]. In addition, a set of non-anticipativity constraints [41] is included to ensure that reserves committed in the day-ahead stage are actually available in the future real-time whether they are required. Although this model is economicallydriven, the focus is put on the availability of the reserves that these limited-energy devices (EVs) may provide to the system. In the current framework of concern about reliability on distribution networks, where most of the EV aggregators are expected to be connected, it seems clear that the ability to provide a reliable reserve should be specially taking into account.

The main contribution of this paper is the development of a mixed-integer robust lineal model through which an aggregator of EVs can find out the optimal joint scheduling of the energy and reserve to be committed in the day-ahead, ensuring the availability of the committed reserve whether it is required in the future real-time. To the best of our knowledge, the actual availability of the reserve committed by an aggregator has not been previously formulated. The uncertainty in the driving pattern of EV owners is included through a robust approach. It is also worth mentioning that the proposed model explicitly considers the ability of the EV aggregator to commit reserve under the idle status, i.e., the status in which the aggregator is not charging or discharging.

The remainder of this paper is organized as follows. Section 2 provides an overall description of the model. In Section 3, the mixed-integer linear problem is formulated and the robust approach is described. Results over a 24-h case study are presented in Section 4 and discussed in Section 5. Finally, conclusions in Section 6 close the paper. 


\section{Model Description}

In the proposed model, the aggregator performs a simultaneous optimization of the energy to charge (or discharge) from (or to) the grid, as well as the upward or downward reserve power that will be available in a future real-time. The amount of energy committed as reserve depends on the type of reserve provided. For the sake of simplicity, this work considers the same time interval for energy and reserve, which is one hour. As previously stated, the main goal of this study is the development of a model in which the availability of the reserve committed by the aggregator in the day-ahead stage can be ensured in a future the real-time. To this end, two main features are included in the proposed model: on one hand, a set of non-anticipativity constraints prevent from unavailable future states, and, on the other hand, the uncertainty related to the driving pattern of EV owners is modeled through a robust approach. Mathematically, the proposed model is posed as a mixed-integer robust linear problem in which binary variables are used to consider the charging, discharging or idle status of the aggregator.

This work assumes a population-based EV aggregation [42] in which all EVs have the same battery and efficiency. Although it would be straightforward to include several models of EV cars merged by battery type, as in [35], only one is considered in order to present a clear formulation. In the same sense, battery degradation is ignored, although it could be easily included as an additional cost in the objective function, as in the stochastic model in [30]. On the other hand, some constraints usually considered in the literature, such as the users' preferences, in terms of a lower bound on the departure state of charge, are then considered in an aggregated formulation.

Two main uncertainty sources are usually modeled in previous published studies: the energy and reserve prices and the EV owners driving behavior. In this work, energy and reserve prices are assumed as exogenous parameters. Several previously published papers make this assumption, for instance in [39], where the aggregator represents an EV parking lot included in a smart grid in which the grid operator handle all the uncertainty sources in the grid. An alternative to this simplifying assumption could be a robust approach to this objective function values, as proposed in [43]. However, in order to meet the goal of a reliable profile of committed reserve, an appropriate modeling of the uncertainty regarding the EV driving pattern is required. In this work, we propose a cardinality-constrained robust optimization formulation [44]. Three uncertain parameters are included in the model: The number of EVs plugged into the parking lot at each time and available to follow the aggregator operation schedule, the total amount of energy leaving the parking at each time, and the total amount of energy arriving at the parking at each time. The two latter parameters correspond to the aggregated amount of energy of those cars departing from, and arriving at, the parking at each time, respectively. It should be noted that, unlike other models focusing the optimal operation of an aggregator, in the proposed model EV car owners are not constrained to only charge at the parking managed by the aggregator. Note that a set of cars may arrive at the parking with a higher amount of energy than they had when leaving it if they are, for instance, recharged at work before commuting back home. Several works may be found in the literature modeling the uncertainty regarding the EV driving pattern, for instance in [45]. Although a precise modeling of the parameters defining this uncertainty source is beyond the scope of this paper, it seems clear that the proposed robust approach fits fine with the goal of formulating a solution procedure to determine the optimal operation of an aggregator providing reliable reserve to the system.

\section{Model Formulation}

In this section, we describe the formulation of the proposed model. In Section 3.1, the formulation of the decision-making problem faced by the EV-aggregator is presented as a mixed-integer linear problem. In Section 3.2, the robust formulation of those constraints including uncertain parameters is provided. Finally, in Section 3.3, we recap the complete robust mixed-integer linear problem. 


\subsection{Decision-Making Problem}

The mixed-integer linear problem to find out the energy and reserve to be committed by an EV aggregator in the day-ahead stage is formulated below. A wide tilde $(\sim)$ denotes those parameters subject to uncertain values. Variables are expressed in lowercase and parameters in uppercase. In this formulation, all continuous variables are non-negative.

The objective function (1) includes a first term related to the profits from energy trading while the second term represents the profit for providing reserve.

$$
\text { Minimize } \sum_{T} \Delta t \cdot\left[C_{t}^{C h} \cdot p_{t}^{C h}-C_{t}^{D c h} \cdot p_{t}^{D c h}\right]-\Delta t \cdot\left[C_{t}^{U P} \cdot r_{t}^{U P}+C_{t}^{D N} \cdot r_{t}^{D N}\right]
$$

where variables $p_{t}^{C h}$ and $p_{t}^{D c h}$ are the charging and discharging powers, and $r_{t}^{U P}$ and $r_{t}^{D N}$ are the upward and downward reserves, respectively. The parameter multiplying each variable is the corresponding price, and $\Delta t$ is the time duration of each period in the time horizon $(\mathrm{T})$.

The constraints bounding this optimization problem follow.

The total amount of upward reserve $r_{t}^{U P}$ in (2), or downward reserve $r_{t}^{D N}$ in (3), is achieved by taking into account the EV aggregator status; i.e., upward reserve at time $t$ may be provided while charging $\left(r c_{t}^{U P}\right)$, discharging $\left(r d_{t}^{U P}\right)$ or idle $\left(r i_{t}^{U P}\right)$ status, and downward reserve at time $t$ may be provided while charging $\left(r c_{t}^{D N}\right)$, discharging $\left(r d_{t}^{D N}\right)$ or idle $\left(r i_{t}^{D N}\right)$ status. Parameters $R_{t}^{U P, \max }$ and $R_{t}^{D N, \max }$ limit the upward and downward reserves at time $t$ in (4) and (5), respectively.

$$
\begin{gathered}
r_{t}^{U P}=r c_{t}^{U P}+r d_{t}^{U P}+r i_{t}^{U P}, \quad \forall t \\
r_{t}^{D N}=r c_{t}^{D N}+r d_{t}^{D N}+r i_{t}^{D N}, \quad \forall t \\
r_{t}^{U P} \leq R_{t}^{U P, \max }, \quad \forall t \\
r_{t}^{D N} \leq R_{t}^{D N, \max }, \quad \forall t
\end{gathered}
$$

Due to physical or contractual reasons, the power exchanged between the EV aggregator and the grid is bounded. These limits must be met under any possible status: charging in (6), discharging in (7) and idle in (8) and (9).

$$
\begin{gathered}
p_{t}^{C h}+r c_{t}^{D N} \leq C A P^{C h} \cdot v_{t}^{C h}, \quad \forall t \\
p_{t}^{D c h}+r d_{t}^{U P} \leq C A P^{D c h} \cdot v_{t}^{D c h}, \quad \forall t \\
r i_{t}^{U P} \leq C A P^{D c h} \cdot v_{t}^{I d}, \quad \forall t \\
r i_{t}^{D N} \leq C A P^{C h} \cdot v_{t}^{I d}, \quad \forall t
\end{gathered}
$$

where the $C A P^{C h}$ and $C A P^{D c h}$ are the connection capacity bounds in the charging and discharging status, respectively; $v_{t}^{C h}$ and $v_{t}^{D c h}$ are the binary variables associated to the charging and discharging status, respectively, and the continuous variable $v_{t}^{I d}$ denotes the idle status. The relationship among these three variables is established in (10)-(12). Equation (10) prevent simultaneous charging and discharging, and the joint consideration of (10)-(12) ensures the binary behaviour of the continuous variable $v_{t}^{I d}$ : note that $v_{t}^{I d}=1$ if, and only if, both binary variables are zero, while $v_{t}^{I d}=0$ otherwise.

$$
\begin{gathered}
v_{t}^{C h}+v_{t}^{D c h} \leq 1, \quad \forall t \\
v_{t}^{I d}=1-v_{t}^{C h}-v_{t}^{D c h}, \quad \forall t \\
v_{t}^{C h}, v_{t}^{D c h} \in\{0,1\}, \quad \forall t
\end{gathered}
$$

On the other hand, the power exchanged between the aggregator and the grid is also limited by the number of EVs plugged into the parking lot. As previously stated in the set of constrains regarding the connection capacity, these bounds must be met under any possible 
status: charging in (13) and (14), discharging in (15) and (16) and idle in (17) and (18). Note that, since all variables are non-negative, the left-hand side of (13) sets the charging power as the upper bound for the upward reserve in the charging status and, equivalently, the left-hand side of (16) sets the discharging power as the upper bound for the downward reserve in the discharging status. For the same reason, the left-hand side of (14) and (15) are not actually required but are included for the sake of clarity.

$$
\begin{aligned}
0 \leq p_{t}^{C h}-r c_{t}^{U P} & \leq \tilde{N}_{t} \cdot N^{T o t} \cdot P_{E V}^{C h} \cdot v_{t}^{C h}, \quad \forall t \\
0 \leq p_{t}^{C h}+r c_{t}^{D N} & \leq \tilde{N}_{t} \cdot N^{T o t} \cdot P_{E V}^{C h} \cdot v_{t}^{C h}, \quad \forall t \\
0 \leq p_{t}^{D c h}+r d_{t}^{U P} & \leq \tilde{N}_{t} \cdot N^{T o t} \cdot P_{E V}^{D c h} \cdot v_{t}^{D c h}, \quad \forall t \\
0 \leq p_{t}^{D c h}-r d_{t}^{D N} & \leq \tilde{N}_{t} \cdot N^{T o t} \cdot P_{E V}^{D c h} \cdot v_{t}^{D c h}, \quad \forall t \\
r i_{t}^{U P} \leq \tilde{N}_{t} \cdot N^{T o t} \cdot P_{E V}^{D c h} \cdot v_{t}^{I d}, \quad \forall t & \\
r i_{t}^{D N} & \leq \tilde{N}_{t} \cdot N^{T o t} \cdot P_{E V}^{C h} \cdot v_{t}^{I d}, \quad \forall t
\end{aligned}
$$

where $N^{T o t}$ in the total number of EVs, the uncertain parameter $\tilde{N}_{t}$ is the percentage (in per unit) of EVs plugged into the parking lot, and $P_{E V}^{C h}$ and $P_{E V}^{D c h}$ are, respectively, the charging and discharging power of the EV.

Regarding energy, this model includes two sets of constraints related to the lower and upper bounds of the state of charge of the aggregator. Firstly, the minimum and maximum values of the state of charge at any time are bounded: (19) presents the lower bound on the minimum value of the state of charge, while (20) is the upper bound on the maximum value.

$$
\begin{aligned}
& \widetilde{N}_{t-1} \cdot N^{T o t} \cdot E_{E V, t-1}^{\text {min }}+\widetilde{E}_{t}^{i n}-\widetilde{E}_{t}^{o u t} \leq e_{t}^{\text {min }}, \quad \forall t \\
& e_{t}^{\max } \leq \widetilde{N}_{t-1} \cdot N^{T o t} \cdot E_{E V, t-1}^{\max }+\widetilde{E}_{t}^{i n}-\widetilde{E}_{t}^{o u t}, \quad \forall t
\end{aligned}
$$

where $E_{E V, t}^{\min }$ and $E_{E V, t}^{\max }$ are the lowest and highest values set for the state of charge of the $\mathrm{EV}$ at time $t$, respectively; the uncertain parameters $\widetilde{E}_{t}^{i n}$ and $\widetilde{E}_{t}^{\text {out }}$ are the total amount of energy corresponding to those EVs arriving at, and departing from, the parking lot at time $t$, respectively; and variables $e_{t}^{\min }$ and $e_{t}^{\max }$ are the lowest and highest values, respectively, of the state of charge of the aggregator a time $t$.

In addition, the non-anticipativity constraints are formulated in (21)-(26). These constraints are included to prevent from unavailable states in the future real-time [41], i.e., whatever the evolution of the state of charge in the coming real-time, depending on the eventual deployment (or not) of the committed reserves, the aggregator should be able to provide the upward and downward reserves committed in the day-ahead stage. In (21)-(23), the upper bound of the minimum value of the state of charge $\left(e_{t}^{\min }\right)$ are presented, while (24)-(26) formulate the lower bound of the maximum value of the state of charge $\left(e_{t}^{\max }\right)$.

$$
\begin{aligned}
& e_{t}^{\min } \leq e_{t-1}^{\min }+\widetilde{E}_{t}^{i n}-\widetilde{E}_{t}^{\text {out }}-\frac{\Delta t}{\eta^{D c h}} \cdot\left(p_{t}^{D c h}+r d_{t}^{U P}\right)+M \cdot\left(1-v_{t}^{D c h}\right), \quad \forall t \\
& e_{t}^{\text {min }} \leq e_{t-1}^{\text {min }}+\widetilde{E}_{t}^{i n}-\widetilde{E}_{t}^{o u t}+\eta^{C h} \cdot \Delta t \cdot\left(p_{t}^{C h}-r c_{t}^{U P}\right)+M \cdot\left(1-v_{t}^{C h}\right), \quad \forall t \\
& e_{t}^{\min } \leq e_{t-1}^{\min }+\widetilde{E}_{t}^{i n}-\widetilde{E}_{t}^{\text {out }}-\frac{\Delta t}{\eta^{D c h}} \cdot r i_{t}^{U P}+M \cdot\left(1-v_{t}^{I d}\right), \quad \forall t \\
& e_{t}^{\max } \geq e_{t-1}^{\max }+\widetilde{E}_{t}^{i n}-\widetilde{E}_{t}^{\text {out }}+\eta^{C h} \cdot \Delta t \cdot\left(p_{t}^{C h}+r c_{t}^{D N}\right)-M \cdot\left(1-v_{t}^{C h}\right), \quad \forall t \\
& e_{t}^{\max } \geq e_{t-1}^{\max }+\widetilde{E}_{t}^{i n}-\widetilde{E}_{t}^{\text {out }}-\frac{\Delta t}{\eta^{D c h}} \cdot\left(p_{t}^{D c h}-r d_{t}^{D N}\right)-M \cdot\left(1-v_{t}^{D c h}\right), \quad \forall t
\end{aligned}
$$




$$
e_{t}^{\max } \geq e_{t-1}^{\max }+\widetilde{E}_{t}^{i n}-\widetilde{E}_{t}^{o u t}+\eta^{C h} \cdot \Delta t \cdot r i_{t}^{D N}-M \cdot\left(1-v_{t}^{I d}\right), \quad \forall t
$$

where parameters $\eta^{C h}$ and $\eta^{D c h}$ are the charging and discharging efficiencies, respectively, and $\mathrm{M}$ refers to a large positive number.

Finally, the boundary constraints on the initial and final state of charge of the EV aggregator are stated in (27) and (28), respectively.

$$
\begin{array}{ll}
e_{t-1}^{\min }=e_{t-1}^{\max }=E_{i n i}, & \text { for } t=1 \\
e_{t}^{\min } \geq E_{\text {ini }}, & \text { for } t=T
\end{array}
$$

where $E_{\text {ini }}$ is the initial state of charge of the EV aggregator.

\subsection{Robust Formulation}

The problem formulated in (1)-(28) includes three uncertain parameters $\left(\widetilde{N}_{t}, \widetilde{E}_{t}^{i n}\right.$, and $\widetilde{E}_{t}^{\text {out }}$ ) in Equations (13)-(26). In order to handle these uncertainty sources, a cardinalityconstrained robust approach is used [44]. Any uncertain parameter $\tilde{X}$ takes values according to a symmetric distribution with mean equal to the expected value $(\bar{X})$ in the interval $[\bar{X}-\widehat{X}, \bar{X}+\widehat{X}]$. In this work, we assume the amplitude of the semi-interval $(\widehat{X})$ as a percentage $(\sigma$, in per unit) of the mean value, i.e., $\widehat{X}=\sigma \cdot \bar{X}$. Then, any uncertain parameter may be expressed as: $\tilde{X} \in[\bar{X}-\sigma \cdot \bar{X}, \bar{X}+\sigma \cdot \bar{X}]$. By means of the cardinalityconstrained robust formulation, an inequality constrained including uncertain parameters is reformulated by adding a robust counterpart and one additional constraint for each uncertain parameter included in the original constraint. The robust counterpart includes a controllable parameter, the budget of uncertainty $(\Gamma)$, that is a positive parameter ranging from 0 (deterministic case assuming the expected value) to the summation of the number of uncertain parameters in the constraint (full robust formulation). This parameter is used to reduce the level of conservatism of this technique, the robust optimization, intended for optimizing the worst-case scenario. More information about how to set the cardinality-constrained robust formulation of a constraint including uncertain parameters may be found in [44].

The first constraint including an uncertain parameter in the optimization problem formulated in Section 3.1 is the right-hand side constraint in (13). The robust formulation of this constraint is (29) and (30):

$$
\begin{gathered}
p_{t}^{C h}-r c_{t}^{U P}+\Gamma_{t}^{C U} \cdot z_{t}^{C U} \leq \bar{N}_{t} \cdot N^{T o t} \cdot P_{E V}^{C h} \cdot v_{t}^{C h}, \quad \forall t \\
z_{t}^{C U} \geq \sigma_{t}^{N_{E V}} \cdot \bar{N}_{t} \cdot N^{T o t} \cdot P_{E V}^{C h} \cdot v_{t}^{C h}, \quad \forall t
\end{gathered}
$$

where the budget of uncertainty $\left(\Gamma_{t}^{C U}\right)$ is multiplied by the auxiliary non-negative continuous variable $z_{t}^{C U}$, and where the additional constraint (30) sets the lower bound of this auxiliary variable $\left(z_{t}^{C U}\right)$. Note that, since only one uncertain parameter is included in (13), only one auxiliary variable and one additional constraint are required.

Accordingly, constraints (31)-(36) are the robust formulation of right-hand side constraints of (14)-(16), while constraints (37)-(40) are the robust formulation of (17) and (18).

$$
\begin{gathered}
p_{t}^{C h}+r c_{t}^{D N}+\Gamma_{t}^{C D} \cdot z_{t}^{C D} \leq \bar{N}_{t} \cdot N^{T o t} \cdot P_{E V}^{C h} \cdot v_{t}^{C h}, \quad \forall t \\
z_{t}^{C D} \geq \sigma_{t}^{N_{E V}} \cdot \bar{N}_{t} \cdot N^{T o t} \cdot P_{E V}^{C h} \cdot v_{t}^{C h}, \quad \forall t \\
p_{t}^{D c h}+r d_{t}^{U P}+\Gamma_{t}^{D U} \cdot z_{t}^{D U} \leq \bar{N}_{t} \cdot N^{T o t} \cdot P_{E V}^{D c h} \cdot v_{t}^{D c h}, \quad \forall t \\
z_{t}^{D U} \geq \sigma_{t}^{N_{E V}} \cdot \bar{N}_{t} \cdot N^{T o t} \cdot P_{E V}^{D c h} \cdot v_{t}^{D c h}, \quad \forall t \\
p_{t}^{D c h}-r d_{t}^{D N}+\Gamma_{t}^{D D} \cdot z_{t}^{D D} \leq \bar{N}_{t} \cdot N^{T o t} \cdot P_{E V}^{D c h} \cdot v_{t}^{D c h}, \quad \forall t
\end{gathered}
$$




$$
\begin{gathered}
z_{t}^{D D} \geq \sigma_{t}^{N_{E V}} \cdot \bar{N}_{t} \cdot N^{T o t} \cdot P_{E V}^{D c h} \cdot v_{t}^{D c h}, \quad \forall t \\
r i_{t}^{U P}+\Gamma_{t}^{I U} \cdot z_{t}^{I U} \leq \bar{N}_{t} \cdot N^{T o t} \cdot P_{E V}^{D c h} \cdot v_{t}^{I d}, \quad \forall t \\
z_{t}^{I U} \geq \sigma_{t}^{N_{E V}} \cdot \bar{N}_{t} \cdot N^{T o t} \cdot P_{E V}^{D c h} \cdot v_{t}^{I d}, \quad \forall t \\
r i_{t}^{D N}+\Gamma_{t}^{I D} \cdot z_{t}^{I D} \leq \bar{N}_{t} \cdot N^{T o t} \cdot P_{E V}^{C h} \cdot v_{t}^{I d}, \quad \forall t \\
z_{t}^{I D} \geq \sigma_{t}^{N_{E V}} \cdot \bar{N}_{t} \cdot N^{T o t} \cdot P_{E V}^{C h} \cdot v_{t}^{I d}, \quad \forall t
\end{gathered}
$$

On the other hand, in (19) there are three uncertain parameters $\left(\widetilde{N}_{t-1}, \widetilde{E}_{t}^{\text {in }}\right.$ and $\left.\widetilde{E}_{t}^{\text {out }}\right)$. In this case, the robust formulation of (19), presented in (41)-(44), requires four non-negative auxiliary variables and three additional constraints. This is an adequate example of the most general case of conversion using the cardinality-constrained robust formulation. Regarding the auxiliary variables, one of them $\left(z_{t}^{\min }\right)$ multiplies the budget of uncertainty $\left(\Gamma_{t}^{\text {min }}\right)$, while each one of the three other $\left(w_{t}^{\min , N_{E V}}, w_{t}^{\min , E_{i n}}\right.$ and $\left.w_{t}^{\text {min }, E_{\text {out }}}\right)$ corresponds to an uncertain parameter. Each additional constraint in (42)-(44) sets a lower bound for the sum of $z_{t}^{\text {min }}$ and the corresponding auxiliary variable.

$$
\begin{gathered}
e_{t}^{\text {min }}-\Gamma_{t}^{\text {min }} \cdot z_{t}^{\text {min }}-w_{t}^{\text {min }, N_{E V}}-w_{t}^{\text {min }, E_{\text {in }}}-w_{t}^{\text {min }, E_{\text {out }}} \geq \\
\bar{N}_{t-1} \cdot N^{\text {Tot }} \cdot E_{E V, t-1}^{\text {min }}+\bar{E}_{t}^{\text {in }}-\bar{E}_{t}^{\text {out }}, \quad \forall t \\
z_{t}^{\text {min }}+w_{t}^{\text {min }, N_{E V}} \geq \sigma_{t}^{N_{E V}} \cdot \bar{N}_{t-1} \cdot N^{\text {Tot }} \cdot E_{E V, t-1}^{\text {min }}, \quad \forall t \\
z_{t}^{\text {min }}+w_{t}^{\text {min }, E_{\text {in }}} \geq \sigma_{t}^{E_{\text {in }}} \cdot \bar{E}_{t}^{\text {in }}, \quad \forall t \\
z_{t}^{\text {min }}+w_{t}^{\text {min }, E_{\text {out }}} \geq \sigma_{t}^{E_{\text {out }}} \cdot \bar{E}_{t}^{\text {out }}, \quad \forall t
\end{gathered}
$$

Accordingly, the robust formulation of (20) is included in (45) and the three additional constraints in (46)-(48).

$$
\begin{gathered}
e_{t}^{\max }+\Gamma_{t}^{\text {max }} \cdot z_{t}^{\text {max }}+w_{t}^{\text {max }, N_{E V}}+w_{t}^{\text {max }, E_{\text {in }}}+w_{t}^{\text {max }, E_{\text {out }}} \leq \\
\bar{N}_{t-1} \cdot N^{\text {Tot }} \cdot E_{E V, t-1}^{\text {max }}+\bar{E}_{t}^{\text {in }}-\bar{E}_{t}^{\text {out }}, \quad \forall t \\
z_{t}^{\text {max }}+w_{t}^{\text {max }, N_{E V}} \geq \sigma_{t}^{N_{E V}} \cdot \bar{N}_{t-1} \cdot N^{\text {Tot }} \cdot E_{E V, t-1}^{\text {max }}, \quad \forall t \\
z_{t}^{\text {max }}+w_{t}^{\text {max }, E_{\text {in }}} \geq \sigma_{t}^{E_{\text {in }}} \cdot \bar{E}_{t}^{\text {in }}, \quad \forall t \\
z_{t}^{\text {max }}+w_{t}^{\text {max }, E_{\text {out }}} \geq \sigma_{t}^{E_{\text {out }}} \cdot \bar{E}_{t}^{\text {out }}, \quad \forall t
\end{gathered}
$$

Finally, the robust formulation of the non-anticipativity constraints in (21)-(26) are required. Note that three non-anticipativity constraints, (21)-(23), are formulated for $e_{t}^{\min }$, one for each possible status (charging, discharging, or idle), and other three, (24)-(26), are required for $e_{t}^{\max }$. The standard application of the cardinality-constrained formulation to each constraint would result in a high number of auxiliary constraints involving binary variables. In order to avoid the computational burden corresponding to that option, both uncertain parameters $\left(\widetilde{E}_{t}^{i n}\right.$ and $\left.\widetilde{E}_{t}^{\text {out }}\right)$ are merged into an equivalent uncertain parameter $\left(\widetilde{E}_{t}^{\text {in }}-\widetilde{E}_{t}^{\text {out }}\right)$. The new uncertain parameter is also symmetrical, which mean equals $\bar{E}_{t}^{\text {in }}-\bar{E}_{t}^{\text {out }}$ and with a semi-amplitude of the interval $\sigma_{t}^{E_{\text {in }}} \cdot \bar{E}_{t}^{\text {in }}+\sigma_{t}^{E_{\text {out }}} \cdot \bar{E}_{t}^{\text {out }}$. Note that this change reduces the required number of both additional constraints and auxiliary variables.

The robust formulation of (21) is included in (49) and (50):

$$
e_{t}^{\min }+\Gamma_{N A, t}^{\min , C} \cdot z_{N A, t}^{\min , C} \leq
$$




$$
\begin{gathered}
e_{t-1}^{\min }+\bar{E}_{t}^{\text {in }}-\bar{E}_{t}^{\text {out }}+\eta^{C h} \cdot \Delta t \cdot\left(p_{t}^{C h}-r c_{t}^{U P}\right)+M \cdot\left(1-v_{t}^{C h}\right), \quad \forall t \\
z_{N A, t}^{\min , C} \geq\left(\sigma_{t}^{E_{\text {in }}} \cdot \bar{E}_{t}^{\text {in }}+\sigma_{t}^{E_{\text {out }}} \cdot \bar{E}_{t}^{\text {out }}\right) \cdot v_{t}^{C h}, \quad \forall t
\end{gathered}
$$

Accordingly, the robust formulation of the non-anticipativity constraints in (22)-(26) are included in (51)-(60):

$$
\begin{aligned}
& e_{t}^{\min }+\Gamma_{N A, t}^{\min , D} \cdot z_{N A, t}^{\min , D} \leq \\
& e_{t-1}^{m i n}+\bar{E}_{t}^{i n}-\bar{E}_{t}^{\text {out }}-\frac{\Delta t}{\eta^{D c h}} \cdot\left(p_{t}^{D c h}+r d_{t}^{U P}\right)+M \cdot\left(1-v_{t}^{D c h}\right), \quad \forall t \\
& z_{N A, t}^{m i n, D} \geq\left(\sigma_{t}^{E_{i n}} \cdot \bar{E}_{t}^{i n}+\sigma_{t}^{E_{\text {out }}} \cdot \bar{E}_{t}^{\text {out }}\right) \cdot v_{t}^{D c h}, \quad \forall t \\
& e_{t}^{\min }+\Gamma_{N A, t}^{\min , I} \cdot z_{N A, t}^{\min , I} \leq \\
& e_{t-1}^{\min }+\bar{E}_{t}^{i n}-\bar{E}_{t}^{\text {out }}-\frac{\Delta t}{\eta^{D c h}} \cdot r i_{t}^{U P}+M \cdot\left(1-v_{t}^{I d}\right), \quad \forall t \\
& z_{N A, t}^{\min , I} \geq\left(\sigma_{t}^{E_{\text {in }}} \cdot \bar{E}_{t}^{\text {in }}+\sigma_{t}^{E_{\text {out }}} \cdot \bar{E}_{t}^{\text {out }}\right) \cdot v_{t}^{I d}, \quad \forall t \\
& e_{t}^{\max }-\Gamma_{N A, t}^{\max , \mathrm{C}} \cdot z_{\mathrm{NA}, \mathrm{m}}^{\max , \mathrm{C}} \geq \\
& e_{t-1}^{\max }+\bar{E}_{t}^{i n}-\bar{E}_{t}^{o u t}+\eta^{C h} \cdot \Delta t \cdot\left(p_{t}^{C h}+r c_{t}^{D N}\right)-M \cdot\left(1-v_{t}^{C h}\right), \quad \forall t \\
& z_{N A, t}^{\max , C} \geq\left(\sigma_{t}^{E_{\text {in }}} \cdot \bar{E}_{t}^{\text {in }}+\sigma_{t}^{E_{\text {out }}} \cdot \bar{E}_{t}^{\text {out }}\right) \cdot v_{t}^{C h}, \quad \forall t \\
& e_{t}^{\max }-\Gamma_{N A, t}^{\max , D} \cdot z_{N A, t}^{\max , D} \geq \\
& e_{t-1}^{m a x}+\bar{E}_{t}^{i n}-\bar{E}_{t}^{\text {out }}-\frac{\Delta t}{\eta^{D c h}} \cdot\left(p_{t}^{D c h}-r d_{t}^{D N}\right)-M \cdot\left(1-v_{t}^{D c h}\right), \quad \forall t \\
& z_{N A, t}^{m a x, D} \geq\left(\sigma_{t}^{E_{i n}} \cdot \bar{E}_{t}^{\text {in }}+\sigma_{t}^{E_{\text {out }}} \cdot \bar{E}_{t}^{\text {out }}\right) \cdot v_{t}^{D c h}, \quad \forall t \\
& e_{t}^{\max }-\Gamma_{N A, t}^{\max , I} \cdot z_{N A, t}^{\max , I} \geq \\
& e_{t-1}^{\max }+\bar{E}_{t}^{i n}-\bar{E}_{t}^{o u t}+\eta^{C h} \cdot \Delta t \cdot r i_{t}^{D N}-M \cdot\left(1-v_{t}^{I d}\right), \quad \forall t \\
& z_{N A, t}^{\max , I} \geq\left(\sigma_{t}^{E_{\text {in }}} \cdot \bar{E}_{t}^{\text {in }}+\sigma_{t}^{E_{\text {out }}} \cdot \bar{E}_{t}^{\text {out }}\right) \cdot v_{t}^{I d}, \quad \forall t
\end{aligned}
$$

\subsection{Robust Mixed-Integer Linear Problem}

Finally, we recap the complete formulation of the proposed mixed-integer linear programming model, in which all continuous variables are non-negative.

The objective function in (1)

Subject to

(2)-(12) \&

left-hand side constraints of (13)-(16)

(deterministic constraints)

(robust constraints)

(boundary constraints)

\section{Results}

This section presents the results over a 24-h case study considering a residential parking lot with a fleet of 100 EVs. According to the proposed model formulation, we assume all EVs are identical, with a battery capacity of $42.2 \mathrm{kWh}$. The maximum charging and discharging powers are both $3.45 \mathrm{~kW}$, and the capacity of the connection between the parking lot and the grid is $300 \mathrm{~kW}$. The charging and discharging efficiencies are both 
set to 0.9 . The upper bounds for the reserve, in both directions, is a $30 \%$ of the charging and discharging power corresponding to the plugged EVs at each time. Figure 1 depicts the energy and reserve prices; these data are taken from the Iberian Electricity Market (MIBEL) [46] on 20 October 2020. Figure 2 shows the expected values of the uncertain parameters in the model over the 24-h horizon. Based on the synthetic data used in [20], a modified version of them is developed to achieve a more restrictive case study. The purpose of this approach is to show the robustness of the proposed formulation even under a particularly adverse situation. All $\sigma$-values in the uncertainty boxes are set to 0.05. Simulations were solved using CPLEX under GAMS [47] on a PC with an Intel Core i5-3470S processor at $2.9 \mathrm{GHz}$ and $16 \mathrm{~GB}$ of RAM.

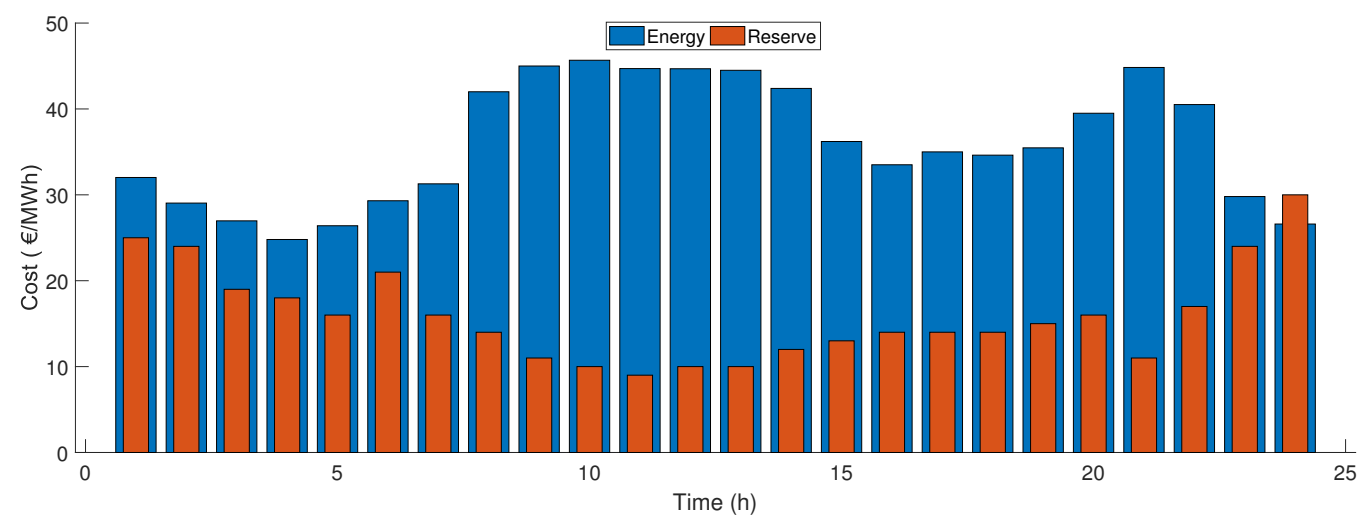

Figure 1. Energy and reserve prices.

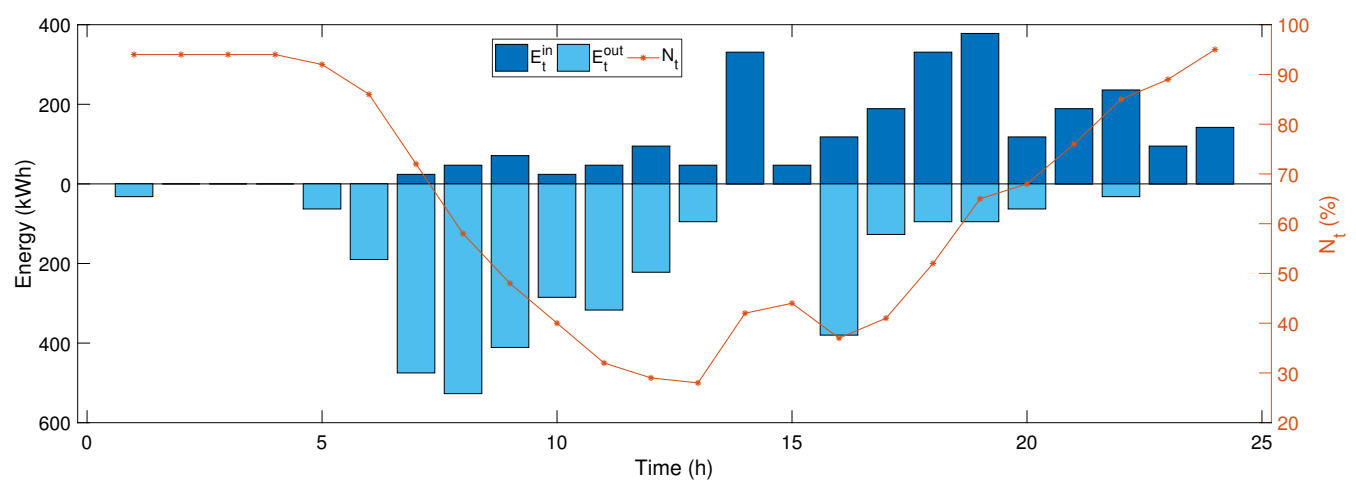

Figure 2. Expected values of the percentage of EVs plugged into the parking lot and total amount of energy arriving at, and departing from, the parking lot.

The main results over this case study are provided next. These main results include the optimal charging and discharging power schedule ( $p_{t}^{C h}$ and $p_{t}^{D c h}$, respectively) and the optimal values of variables bounding the state of charge of the aggregator at each time $\left(e_{t}^{\min }\right.$ and $\left.e_{t}^{\max }\right)$. This section is divided into three blocks: Firstly, the previously described case study is analyzed; then, results over a modified version of this case study are provided; and, finally, the sensitivity of the model to the budget of uncertainty is analyzed.

Figure 3 presents power and reserve results, where Figure $3 a$ shows the charging and discharging powers, and Figure $3 \mathrm{~b}$ depicts the downward and upward reserves. Figure $3 a$ shows the parking lot is charging in 11 periods: as expected, the bulk of the charging is achieved during night-time (all hours before 8); later, in the valley prices in the afternoon (hours 16, 18, and 19); and an additional charging is required at the end of the day to meet the minimum state of charge related to the boundary constraint at the end of the day. Discharging is achieved at the beginning of the morning (from 8 to 10) in those periods with high energy prices, injecting back to the grid part of the energy charged at night; likewise, the discharging at hour 21 is also due to the high energy price. The rest of the 
day, the parking lot remains in the idle status, i.e., without charging or discharging. On the other hand, Figure $3 \mathrm{~b}$ shows reserve prices are not high enough to incentivize the upward reserve: only at hour 24, with a high reserve price and no other constraint bounding at the end of the day, upward reserve is provided. However, the opposite holds in the case of the downward reserve. This type of reserve is provided under the three possible status: while charging (at hours 1, 2, 6, 16, 18, 19, and 24), discharging (at hour 21) and in the idle status (at hours 15, 17, 20, 22, and 23). The capacity of the connection between the EV aggregator and the grid is the bounding constraint limiting the charging status at hours 3,4, and 5, when no reserves are scheduled. Note that, in that period, most of EVs are plugged into the parking lot. However, in hour 2, although this capacity constraint is also limiting, the charging power has to be reduced $(292.71 \mathrm{kWh})$ to ensure the future availability of the committed downward reserve $(97.29 \mathrm{kWh})$. Then, when EVs start leaving the parking lot, the limiting constraints are those related to the number of available EVs. It should be also noted that no power or reserve are scheduled in the period between hours 11 and 14, due to the reduced number of EVs plugged into the parking lot. On the other hand, the increasing downward reserve committed at the end of the day follows the curve of EVs plugged into the parking lot.

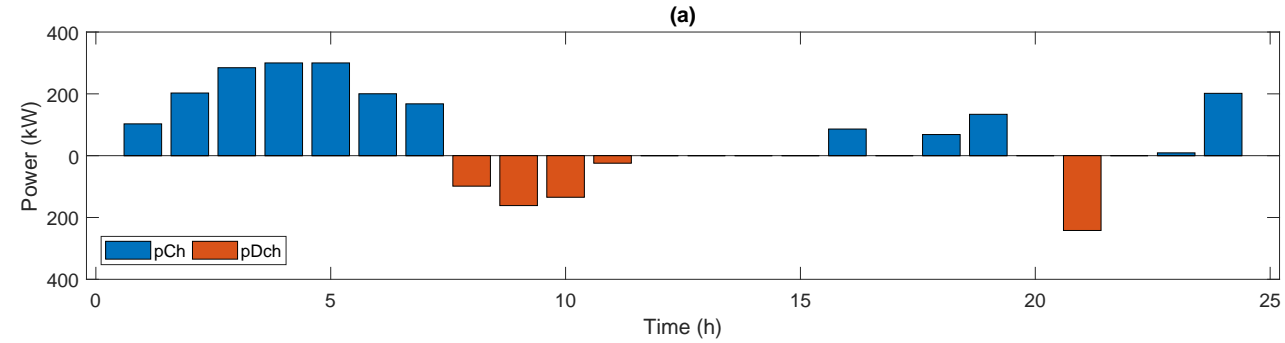

(b)

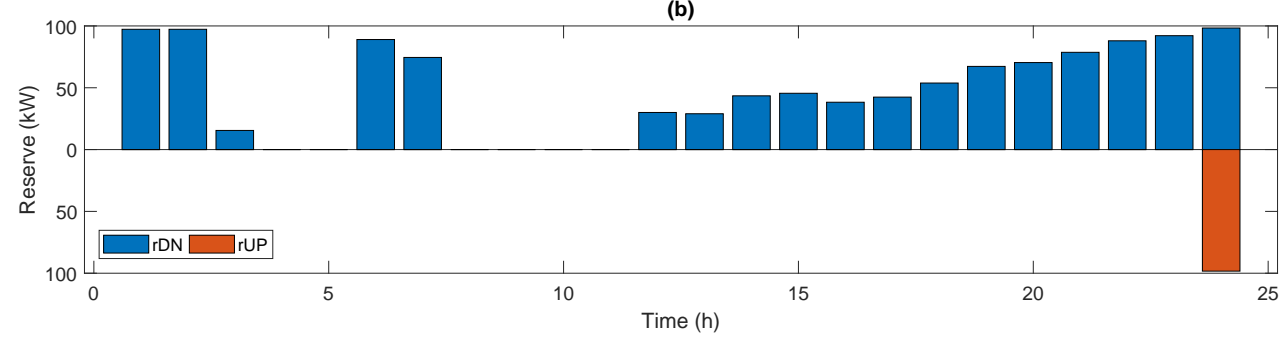

Figure 3. Power and reserve results: (a) Charging and discharging power; (b) downward and upward reserve.

Figure 4 presents the evolution of the lower and upper bounds on the state of charge of the aggregator, i.e., the values along the day of the bounding variables $e_{t}^{\min }$ and $e_{t}^{\max }$. In this figure, the lower and upper bounds on these variables in terms of the three uncertain values are also included (in black color): $E_{t}^{M I N}$ is the lower bound taking into account the expected (mean) values of the uncertain parameters, while $E_{t}^{M A X}$ is the corresponding upper bound. The gap that can be appreciated between the minimum state of charge and its lower bound, or the maximum state of charge and its upper bound, is due to effect of the robust formulation. As it will be shown later, these gaps do not exist if the deterministic version, i.e., with the uncertain parameters fixed at their expected values (all $\Gamma^{\prime}$ 's equal zero), is run. The main reason for the gap existing between variables representing the lower and upper bounds on the state of charge of the aggregator is the commitment of reserves. In order to ensure the availability of the committed reserves, the gap between these two variables $\left(e_{t}^{\min }\right.$ and $\left.e_{t}^{\max }\right)$ has to be increased. This effect may be clearly appreciated in the last hours of the day, where the increasing committed reserve results on an increasing gap between these two variables bounding the state of charge of the aggregator. 


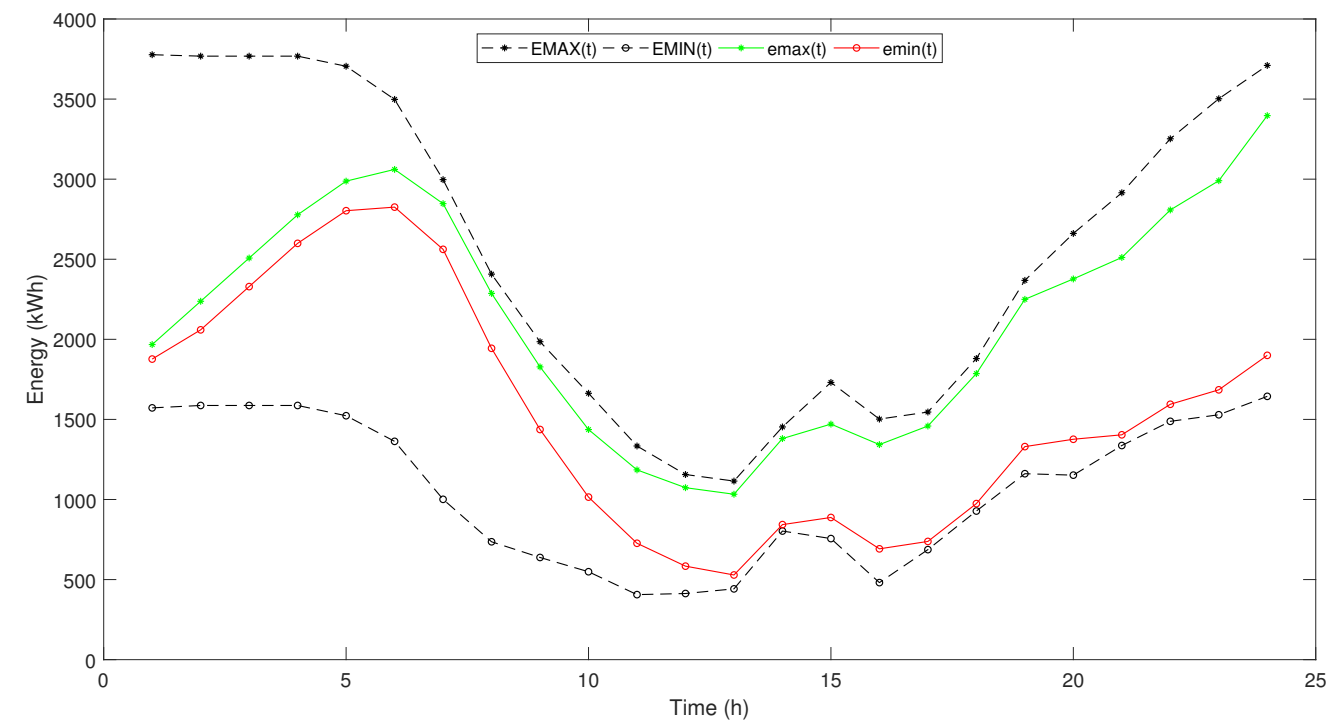

Figure 4. Evolution of bounding variables $e_{t}^{\min }$ and $e_{t}^{\max }$.

In order to analyze the sensitivity of the proposed model with the reserve prices, these input data are changed to define a modified version of the previously described case study: all reserve prices are set to zero, but in hours 5 and 6 , where the price of the downward reserve is set to $30 € / \mathrm{MWh}$, and in the period between hours 13 and 16 , where the upward reserve is set to $40 € / \mathrm{MWh}$. Unlike the previous case study in which reserve prices correspond to values in the wholesale market, these modified reserve prices could correspond to the needs, for instance, of a smart grid with a relevant number of EVs with uncontrolled charging and a relevant number of users with photovoltaic self-consumption. Figure 5 presents the power (a) and reserve (b) results, and Figure 6 shows the lower and upper bounds on the state of charge corresponding to this modified case study.
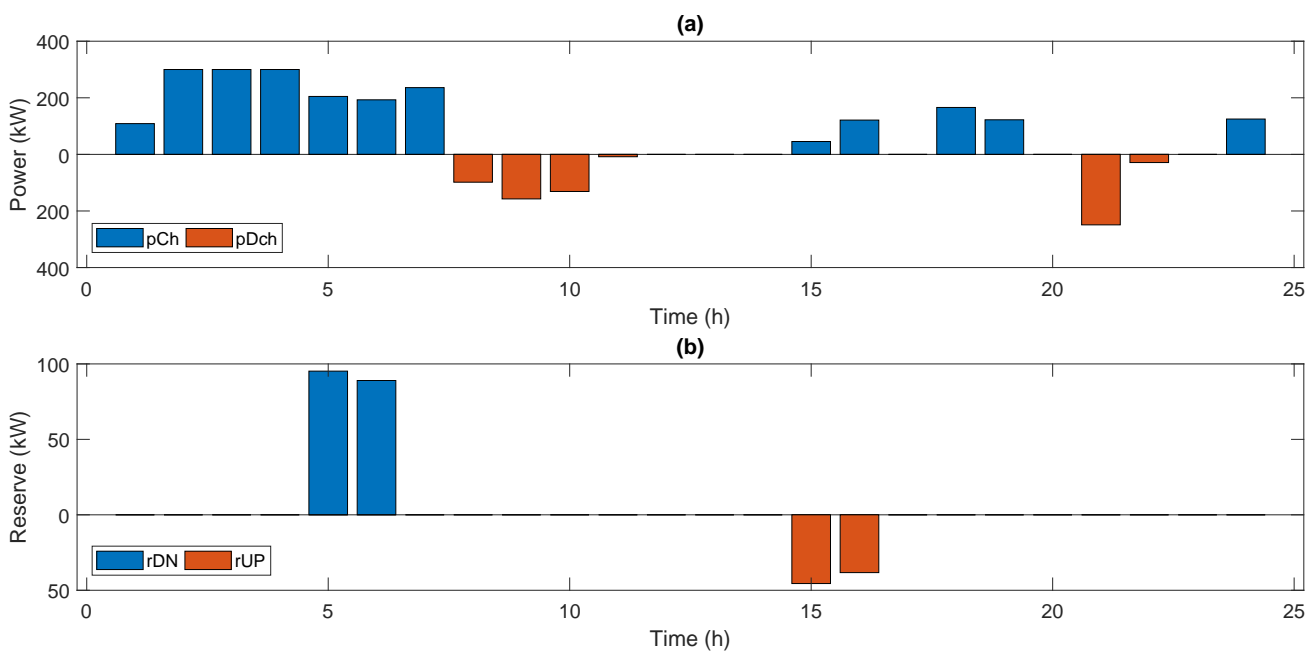

Figure 5. Power and reserve results with modified reserve prices: (a) Charging and discharging power; (b) downward and upward reserve.

In Figure $5 b$ it can be seen that downward reserve is committed in both hours with non-zero prices (5 and 6); however, even though the price of upward reserve is higher than the price of downward reserve in this modified case study, there are only two hours (15 and 16), out of the four with non-zero prices, in which upward reserve is committed. On the other hand, in terms of power and reserve, Figure 5a shows the number of hours in the idle status is reduced: the number of hours in which the aggregator is charging is 12 (instead of 11) while is discharging in $6 \mathrm{~h}$ (instead of 4). By comparing the energy committed in 
this modified case study with the previous one, it can be seen there is an increase in both charging and discharging quantities: from $2017 \mathrm{kWh}$ to $2222 \mathrm{kWh}$ in the case of charging, and from $495 \mathrm{kWh}$ to $673 \mathrm{kWh}$ in the case of discharging. This is due to the fact that reserves are not paid in most of the hours in this modified case study: since low battery capacity has to be preserved to ensure the committed reserve in a future real-time, the aggregator has a wider margin to charge and discharge in order to reduce its energy bill.

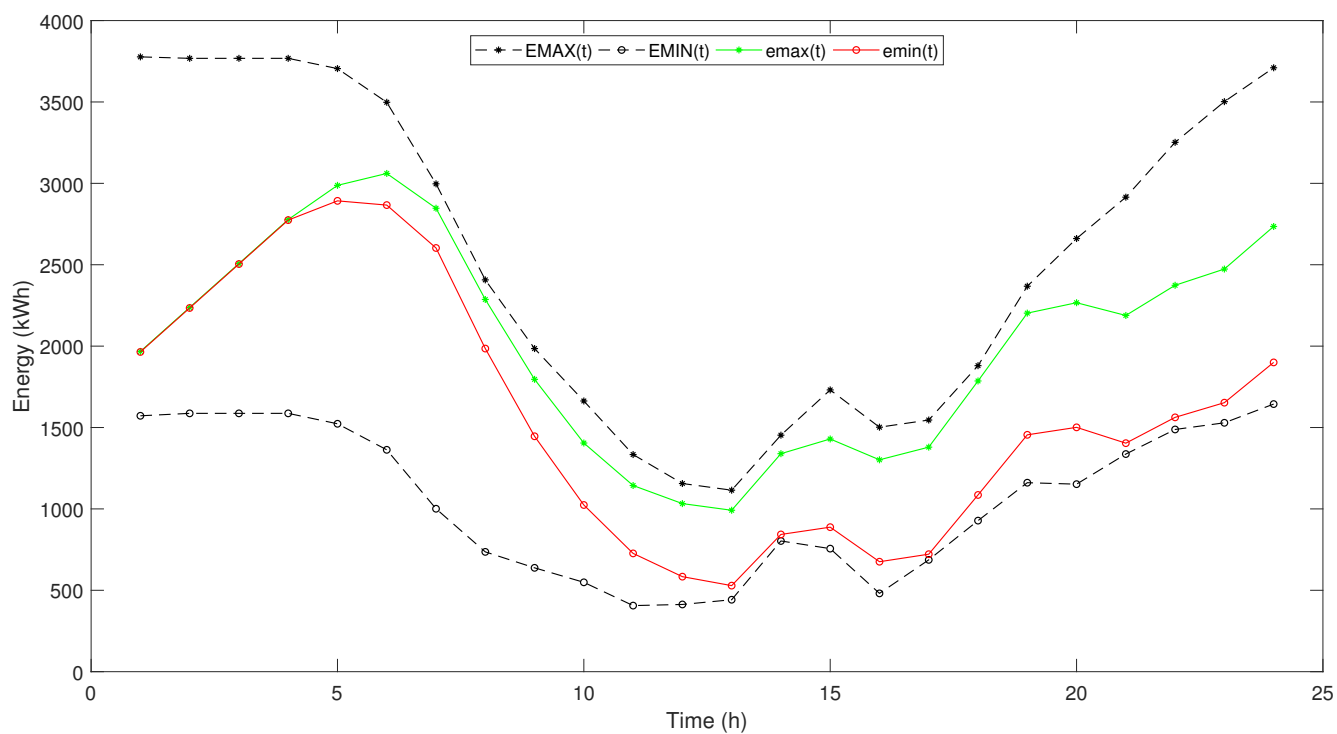

Figure 6. Evolution of bounding variables $e_{t}^{\min }$ and $e_{t}^{\max }$ with modified reserve prices.

The evolution of the lower and upper bounds of the state of charge of the aggregator in this modified case study is depicted in Figure 6. It can be appreciated that the gap between the bounding variables $\left(e_{t}^{\min }\right.$ and $\left.e_{t}^{\max }\right)$ is increased in hours 5 and 6 . This is increase is mainly due to the discharging reserve committed in those hours, see Figure 5b. However, the gap increase achieved in the period between hours 6 and 14, when no reserves are scheduled, are due to the robust formulation of the non-anticipativity constraints: the worst-case value of the uncertainty parameter is accounted for in opposite directions in the lower and upper bounds. This behavior is repeated at the final part of the day, once the gap increase due to the upward reserve committed in hours 15 and 16 is achieved. A deep explanation of the behavior of these bounding variables may be found in Section 5 .

Finally, in order to analyze the sensitivity of the proposed model to the budgets of uncertainty, this case study, with reserve prices provided in Figure 1, is run for three different values of this parameter: (i) the so-called 'full-robust' case, in which all the budgets of uncertainty are set to their highest values; (ii) the 'deterministic' case, in which all of them are zero; and (iii), an 'intermediate' case, in which all budgets of uncertainty are set to their intermediate value. Figure 7 shows the power (a) and reserve (b) results, while Figure 8 depicts the evolution of the lower and upper bounds of the state of charge for these three cases. In both figures, results over the full robust case are identified with subscript 100 , those corresponding the intermediate case are identified with subscript 50 , and subscript 0 is used to the deterministic case. It should be noted that results corresponding to the full robust case (subscript 100) are those presented in Figures 3 and 4. 
(a)

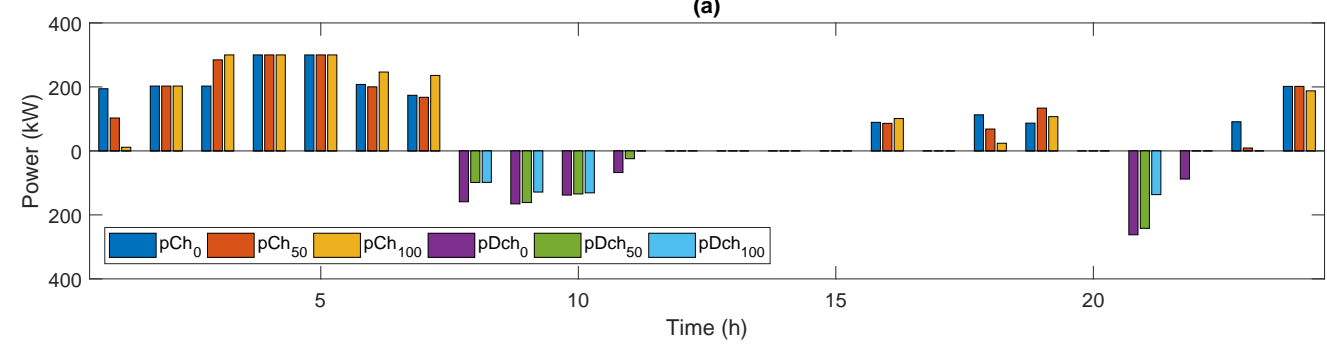

(b)

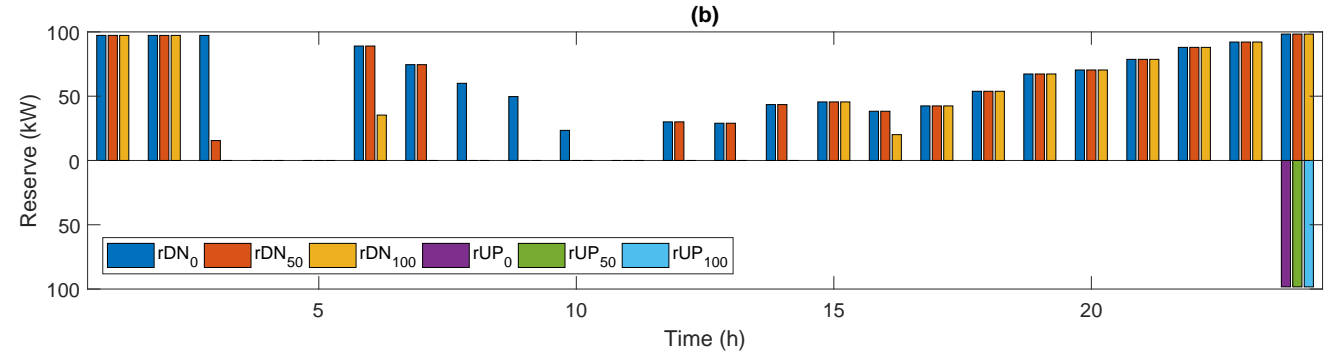

Figure 7. Power (a) and reserve (b) results for different values of the budgets of uncertainty $(\Gamma)$.

It can be appreciated in Figure 7a that the effect of increasing the budgets of uncertainty is a decrease in both the power and reserve committed. The highest committed power, and in both directions, are reached in the deterministic case (a total amount of $2163 \mathrm{kWh}$ while charging, and $880 \mathrm{kWh}$ while discharging); on the other hand, the lowest values are achieved in the full robust case (a total amount of $2017 \mathrm{kWh}$ while charging, and $495 \mathrm{kWh}$ while discharging). The same behavior may be appreciated in the downward reserve results in Figure $7 \mathrm{~b}$, accounting for a total amount of $1366 \mathrm{kWh}$ in the deterministic case, while $887 \mathrm{kWh}$ is achieved in the full robust case. It may be also appreciated in Figure 8, that bounding variables $\left(e_{t}^{\min }\right.$ and $\left.e_{t}^{\max }\right)$ only reach their corresponding bounds ( $E_{t}^{M I N}$ and $E_{t}^{M A X}$, respectively), in the deterministic case. As mentioned above, more details about these bounding variables may be found in Section 5 .

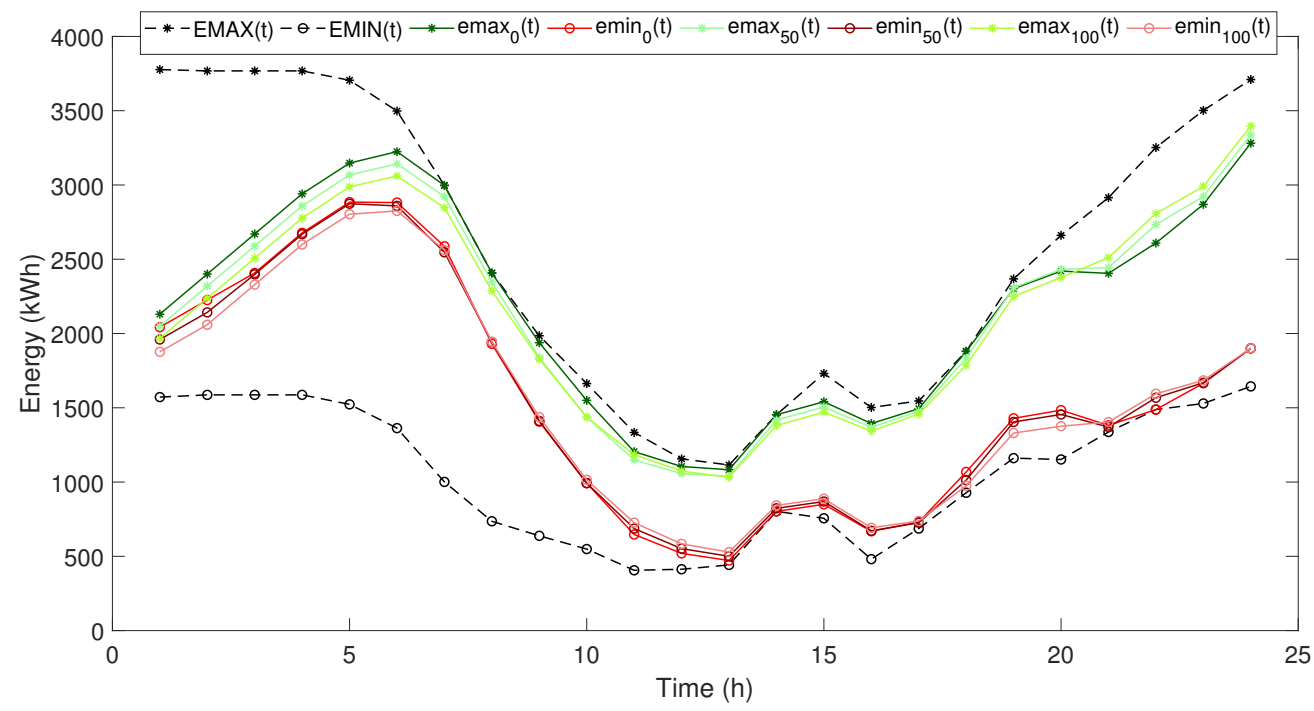

Figure 8. Evolution of bounding variables $e_{t}^{\min }$ and $e_{t}^{\max }$ for different values of the budgets of uncertainty $(\Gamma)$.

The CPU time required to solve the original case study is $954 \mathrm{~s}$ ( $\sim 16 \mathrm{~min})$, while the modified version, in which reserve costs are non-zero values in only $6 \mathrm{~h}$, was solved in only $0.94 \mathrm{~s}$. On the other hand, the deterministic version of the original case study (with all $\Gamma$ parameters set to zero) was solved in $4.06 \mathrm{~s}$, and the case study with intermediate values of the budgets of uncertainty was solved in $328.05 \mathrm{~s}$. ( $\sim 5.5 \mathrm{~min})$. All these CPU times were 
obtained with the optimality relative criterion in CPLEX (optcr) set to zero, i.e., the total $\mathrm{CPU}$ time required to find out the optimal solution of the mixed-integer linear problem.

\section{Discussion}

Results presented in the previous section show the proposed model is able to find out the optimal values of charging and discharging, as well as the optimal reserve values that can be ensured at the day-ahead stage. Although the actual state of charge will depend on the amount of reserve that will be actually deployed in the real-time, the optimal values of bounding variables $e_{t}^{\min }$ and $e_{t}^{\max }$ set the lower and upper bounds, respectively, within which the state of charge of the aggregator is able to ensure the reserves committed in the day-ahead. The original case study (Figure 4), and its modified version (Figure 6), show the evolution of these bounding variables to the state of charge of the aggregator. In view of the results achieved in the previous section, some details about how the proposed model establishes these bounding variables are provided next.

On one hand, each of these bounding variables are limited by the uncertain parameters. The gap between variable $e_{t}^{\min }$ and its lower bound, the parameter $E_{t}^{M I N}$, as well as the gap between variable $e_{t}^{\max }$ and its upper bound, the parameter $E_{t}^{M A X}$, can be appreciated in Figures 4 and 6. This is due to the robust formulation of (19) and (20); note that parameters $E_{t}^{M I N}$ and $E_{t}^{M A X}$ are, respectively, the left-hand side of (19) and the right-hand side of (20), in which the expected values are considered for the uncertain parameters. The effect of the robust formulation is variable $e_{t}^{\min }$ is pushed up from parameter $E_{t}^{M I N}$, while variable $e_{t}^{\max }$ is pushed down from parameter $E_{t}^{M A X}$. This effect of moving away from these limits can even be more clearly seen in Figure 8: the higher the level of uncertainty is considered (i.e., by increasing the budget of uncertainty), the wider the gap between the bounding variable $\left(e_{t}^{\min }\right.$ or $\left.e_{t}^{\max }\right)$ and its corresponding limit $\left(E_{t}^{M I N}\right.$ or $\left.E_{t}^{M A X}\right)$.

On the other hand, the internal gap between these bounding variables $\left(e_{t}^{\min }\right.$ and $\left.e_{t}^{\max }\right)$, according to the non-anticipativity constraints, depends on the uncertain values of the amount of energy departing from, and arriving at, the parking lot at each time, and on the optimal results of the committed reserve. As previously mentioned, results over the modified case study (Figures 5 and 6), when the provision of reserve is only profitable in six hours, clearly show this dependency. The internal gap between $e_{t}^{\min }$ and $e_{t}^{\max }$ in the period from hour 17 to 24 , when no reserves are committed, are due to the robust formulation of the non-anticipativity constraints. On the other, the joined effect of the robust approach and committed reserve causes the increase on this internal gap in hours 5 and 6. However, this gap is not affected by the charging or discharging power. This result can be also appreciated in the results from the modified case study in the period from hour 2 to 4 . In these three hours, the parking lot is charging up to the connection capacity with the grid, but no reserve is committed and no departures, or arrivals, are set for these three hours; then, there is no increase in this internal gap and the evolution of $e_{t}^{\min }$ and $e_{t}^{\max }$ depicts two parallel functions that can be seen in Figure 6.

Finally, results also show a 'bottleneck effect' around hour 13, when the lowest number of EVs is plugged into the parking lot. The idle status, and without any reserve provision, holds from hour 11 to 14 in the original case study (Figure 3), even though at those hours prices are high. The same result is shown in Figure 5 for the modified case study in the period from hours 12 to 14 . This is due to fact that the limited energy availability in the parking lot, due to the low number of plugged EVs, results in a narrowing of the difference between the bounding parameters $E_{t}^{M I N}$ and $E_{t}^{M A X}$. As a consequence, the optimal solution is split into two intervals, before and after this narrowing. In fact, by comparing the results corresponding to the evolution of this bounding variables $\left(e_{t}^{\min }\right.$ and $e_{t}^{\max }$ ) over the original and modified case studies (Figures 4 and 6), it can be appreciated that quite similar results are achieved before hour 13. However, after hour 16, when reserve is last committed in the modified case study, the internal gap between $\left(e_{t}^{\min }\right.$ and $\left.e_{t}^{\max }\right)$ is higher in the original case study due to the total amount of downward reserve committed from hour 17 to 24 . 


\section{Conclusions}

This paper proposes a mixed-integer linear robust optimization model to determine the charging and discharging powers, as well as the downward and upward reserves, to be committed by an EV aggregator in the day-ahead stage. Although it is an economicallydriven model, the focus is put on the capacity of the EV aggregator to provide reliable reserve. To this end, two main features stand out: the robust formulation used to handle the uncertainty sources in the model, and the set of non-anticipativity constraints able to avoid the unavailability of the committed reserves whether they are required in the real-time stage.

From the analyzed and discussed case study some conclusions can be drawn. The proposed formulation is able to set the lower and upper bounds of the state of charge of the aggregator through variables $e_{t}^{\min }$ and $e_{t}^{\max }$. Although the actual state of charge will depend on the amount of reserve that will be actually deployed in the real-time, the optimal solution achieved for these bounding variables set the limits within the aggregator is able to deploy any reserve committed in the day-ahead stage. Two factors are determinant in establishing these two bounding variables: the amount of committed reserves and the level of uncertainty considered in the robust formulation. In terms of reserve provision, an aggregator is more likely to provide downward reserve than upward reserve. In the case study with real prices taken from the MIBEL market, downward reserve is committed in $13 \mathrm{~h}$, while upward reserve is only committed in hour 24 , at the end of the day, hour in which no boundary constraint is limiting this provision of reserve. Taking into account the battery efficiencies and the capacity of injecting power to the grid under the V2G mode, upward reserve is only achieved in those periods with relatively high reserve prices. The degree of conservatism included in the robust approach can be controlled through the budgets of uncertainty: The higher the budget of uncertainty considered, the smaller the margin for the aggregator to optimize its scheduling. Comparing results over the full robust case with those of the deterministic case, a $6.8 \%$ decrease is achieved in the total amount of charging power, a $43.8 \%$ decrease is achieved in the discharging status, and a $35.1 \%$ decrease is obtained in the committed reserve. Finally, whether the availability of reserve is a relevant requirement from the grid operator, a joint optimization of power and reserve should be considered; otherwise, the capacity of the EV aggregator to provide reliable reserve, based on a considerable number of small limited-energy devices, would be severely compromised.

Author Contributions: Conceptualization, J.P.-R. and A.J.-M.; methodology, J.P.-R. and A.J.-M.; software, A.J.-M.; validation, A.J.-M.; formal analysis, J.P.-R. and A.J.-M.; investigation, A.J.-M.; resources, J.P.-R.; writing-review and editing, J.P.-R. and A.J.-M.; supervision, J.P.-R. All authors have read and agreed to the published version of the manuscript.

Funding: The work of J. Pérez-Ruiz was supported in part by the Junta de Andalucia under project UMA18-FEDERJA-150.

Institutional Review Board Statement: Not applicable.

Informed Consent Statement: Not applicable.

Conflicts of Interest: The authors declare no conflict of interest.

\section{References}

1. International Energy Agency (IEA). Global EV Outlook 2020. Entering the Decade of Electric Drive? OECD Publishing: Paris, France, 2020. [CrossRef]

2. Ma, O.; Alkadi, N.; Cappers, P.; Denholm, P.; Dudley, J.; Goli, S.; Hummon, M.; Kiliccote, S.; MacDonald, J.; Matson, N.; et al. Demand Response for Ancillary Services. IEEE Trans. Smart Grid 2013, 4, 1988-1995. [CrossRef]

3. Directive (EU) 2019/944 of the European Parliament and of the Council of 5 June 2019 on common rules for the internal market for electricity and amending Directive 2012/27/EU. Off. J. Eur. Union L 158 2019, 62, 125-200.

4. Niesten, E.; Alkemade, F. How is value created and captured in smart grids? A review of the literature and an analysis of pilot projects. Renew. Sustain. Energy Rev. 2016, 53, 629-638. [CrossRef] 
5. Solanke, T.U.; Khatua, P.K.; Ramachandaramurthy, V.K.; Yong, J.Y.; Tan, K.M. Control and management of a multilevel electric vehicles infrastructure integrated with distributed resources: A comprehensive review. Renew. Sustain. Energy Rev. 2021, 144, 111020. [CrossRef]

6. Amjad, M.; Ahmad, A.; Rehmani, M.H.; Umer, T. A review of EVs charging: From the perspective of energy optimization, optimization approaches, and charging techniques. Transp. Res. Part Transp. Environ. 2018, 62, 386-417. [CrossRef]

7. Tan, K.M.; Ramachandaramurthy, V.K.; Yong, J.Y. Integration of electric vehicles in smart grid: A review on vehicle to grid technologies and optimization techniques. Renew. Sustain. Energy Rev. 2016, 53, 720-732. [CrossRef]

8. Okur, O.; Heijnen, P.; Lukszo, Z. Aggregator's business models in residential and service sectors: A review of operational and financial aspects. Renew. Sustain. Energy Rev. 2021, 139, 110702. [CrossRef]

9. González-Romera, E.; Barrero-González, F.; Romero-Cadaval, E.; Milanés-Montero, M.I. Overview of plug-in electric vehicles as providers of ancillary services. In Proceedings of the 2015 9th International Conference on Compatibility and Power Electronics (CPE), Costa da Caparica, Portugal, 24-26 June 2015; pp. 516-521. [CrossRef]

10. Burger, S.; Chaves-Ávila, J.P.; Batlle, C.; Pérez-Arriaga, I.J. A review of the value of aggregators in electricity systems. Renew. Sustain. Energy Rev. 2017, 77, 395-405. [CrossRef]

11. Minniti, S.; Haque, N.; Nguyen, P.; Pemen, G. Local Markets for Flexibility Trading: Key Stages and Enablers. Energies 2018, 11, 3074. [CrossRef]

12. Jargstorf, J.; Wickert, M. Offer of secondary reserve with a pool of electric vehicles on the German market. Energy Policy 2013, 62, 185-195. [CrossRef]

13. Brandt, T.; Wagner, S.; Neumann, D. Evaluating a business model for vehicle-grid integration: Evidence from Germany. Transp. Res. Part Transp. Environ. 2017, 50, 488-504. [CrossRef]

14. Yang, H.; Xie, X.; Vasilakos, A.V. Noncooperative and Cooperative Optimization of Electric Vehicle Charging Under Demand Uncertainty: A Robust Stackelberg Game. IEEE Trans. Veh. Technol. 2016, 65, 1043-1058. [CrossRef]

15. Aluisio, B.; Conserva, A.; Dicorato, M.; Forte, G.; Trovato, M. Optimal operation planning of V2G-equipped Microgrid in the presence of EV aggregator. Electr. Power Syst. Res. 2017, 152, 295-305. [CrossRef]

16. Baringo, L.; Sánchez Amaro, R. A stochastic robust optimization approach for the bidding strategy of an electric vehicle aggregator. Electr. Power Syst. Res. 2017, 146, 362-370. [CrossRef]

17. Cao, Y.; Huang, L.; Li, Y.; Jermsittiparsert, K.; Ahmadi-Nezamabad, H.; Nojavan, S. Optimal scheduling of electric vehicles aggregator under market price uncertainty using robust optimization technique. Int. J. Electr. Power Energy Syst. 2020, 117, 105628. [CrossRef]

18. Mohiti, M.; Monsef, H.; Lesani, H. A decentralized robust model for coordinated operation of smart distribution network and electric vehicle aggregators. Int. J. Electr. Power Energy Syst. 2019, 104, 853-867. [CrossRef]

19. Gomes, I.; Melicio, R.; Mendes, V. Comparison between Inflexible and Flexible Charging of Electric Vehicles-A Study from the Perspective of an Aggregator. Energies 2020, 13, 5443. [CrossRef]

20. Porras, A.; Fernández-Blanco, R.; Morales, J.M.; Pineda, S. An Efficient Robust Approach to the Day-Ahead Operation of an Aggregator of Electric Vehicles. IEEE Trans. Smart Grid 2020, 11, 4960-4970. [CrossRef]

21. Ur Rehman, U.; Riaz, M.; Wani, M.Y. A robust optimization method for optimizing day-ahead operation of the electric vehicles aggregator. Int. J. Electr. Power Energy Syst. 2021, 132, 107179. [CrossRef]

22. Bessa, R.J.; Matos, M.A. Optimization Models for EV Aggregator Participation in a Manual Reserve Market. IEEE Trans. Power Syst. 2013, 28, 3085-3095. [CrossRef]

23. Bessa, R.J.; Matos, M.A. Optimization models for an EV aggregator selling secondary reserve in the electricity market. Electr. Power Syst. Res. 2014, 106, 36-50. [CrossRef]

24. Goebel, C.; Jacobsen, H. Aggregator-Controlled EV Charging in Pay-as-Bid Reserve Markets With Strict Delivery Constraints. IEEE Trans. Power Syst. 2016, 31, 4447-4461. [CrossRef]

25. Han, B.; Lu, S.; Xue, F.; Jiang, L.; Xu, X. Three-stage electric vehicle scheduling considering stakeholders economic inconsistency and battery degradation. IET Cyber-Phys. Syst. Theory Appl. 2017, 2, 102-110. [CrossRef]

26. Han, B.; Lu, S.; Xue, F.; Jiang, L. Day-ahead electric vehicle aggregator bidding strategy using stochastic programming in an uncertain reserve market. IET Gener. Transm. Distrib. 2019, 13, 2517-2525. [CrossRef]

27. Clairand, J.M. Participation of Electric Vehicle Aggregators in Ancillary Services Considering Users' Preferences. Sustainability 2020, 12, 8. [CrossRef]

28. Pavić, I.; Capuder, T.; Kuzle, I. Value of flexible electric vehicles in providing spinning reserve services. Appl. Energy 2015, 157, 60-74. [CrossRef]

29. Sarker, M.R.; Dvorkin, Y.; Ortega-Vazquez, M.A. Optimal Participation of an Electric Vehicle Aggregator in Day-Ahead Energy and Reserve Markets. IEEE Trans. Power Syst. 2016, 31, 3506-3515. [CrossRef]

30. Alipour, M.; Mohammadi-Ivatloo, B.; Moradi-Dalvand, M.; Zare, K. Stochastic scheduling of aggregators of plug-in electric vehicles for participation in energy and ancillary service markets. Energy 2017, 118, 1168-1179. [CrossRef]

31. Iria, J.; Soares, F.; Matos, M. Optimal supply and demand bidding strategy for an aggregator of small prosumers. Appl. Energy 2018, 213, 658-669. [CrossRef]

32. Iria, J.; Soares, F.; Matos, M. Optimal bidding strategy for an aggregator of prosumers in energy and secondary reserve markets. Appl. Energy 2019, 238, 1361-1372. [CrossRef] 
33. Şengör, I.; Çiçek, A.; Kübra Erenoğlu, A.; Erdinç, O.; Catalão, J.P. User-comfort oriented optimal bidding strategy of an electric vehicle aggregator in day-ahead and reserve markets. Int. J. Electr. Power Energy Syst. 2020, 122, 106194. [CrossRef]

34. Recalde Melo, D.F.; Trippe, A.; Gooi, H.B.; Massier, T. Robust Electric Vehicle Aggregation for Ancillary Service Provision Considering Battery Aging. IEEE Trans. Smart Grid 2018, 9, 1728-1738. [CrossRef]

35. Amamra, S.A.; Marco, J. Vehicle-to-Grid Aggregator to Support Power Grid and Reduce Electric Vehicle Charging Cost. IEEE Access 2019, 7, 178528-178538. [CrossRef]

36. Aldik, A.; Al-Awami, A.T.; Sortomme, E.; Muqbel, A.M.; Shahidehpour, M. A Planning Model for Electric Vehicle Aggregators Providing Ancillary Services. IEEE Access 2018, 6, 70685-70697. [CrossRef]

37. Mohammadnejad, M.; Abdollahi, A.; Rashidinejad, M. Possibilistic-probabilistic self-scheduling of PEVAggregator for participation in spinning reserve market considering uncertain DRPs. Energy 2020, 196, 117108. [CrossRef]

38. Jia, Y.; Mi, Z.; Yu, Y.; Song, Z.; Sun, C. A Bilevel Model for Optimal Bidding and Offering of Flexible Load Aggregator in Day-Ahead Energy and Reserve Markets. IEEE Access 2018, 6, 67799-67808. [CrossRef]

39. Liu, W.; Chen, S.; Hou, Y.; Yang, Z. Optimal Reserve Management of Electric Vehicle Aggregator: Discrete Bilevel Optimization Model and Exact Algorithm. IEEE Trans. Smart Grid 2021, 12, 4003-4015. [CrossRef]

40. Ben-Tal, A.; Nemirovski, A. Robust Optimization; Princeton University Press: Princeton, NJ, USA, 2008.

41. Cobos, N.G.; Arroyo, J.M.; Alguacil, N.; Wang, J. Robust Energy and Reserve Scheduling Considering Bulk Energy Storage Units and Wind Uncertainty. IEEE Trans. Power Syst. 2018, 33, 5206-5216. [CrossRef]

42. Cortés Borray, A.F.; Merino, J.; Torres, E.; Mazón, J. A review of the population-based and individual-based approaches for electric vehicles in network energy studies. Electr. Power Syst. Res. 2020, 189, 106785. [CrossRef]

43. Lim, J.; Park, S. On using cardinality constrained uncertainty for objective coefficients in robust optimization. Optim. Lett. 2021, 15, 1195-1214. [CrossRef]

44. Bertsimas, D.; Sim, M. The Price of Robustness. Oper. Res. 2004, 52, 35-53. [CrossRef]

45. Sarabi, S.; Davigny, A.; Courtecuisse, V.; Riffonneau, Y.; Robyns, B. Potential of vehicle-to-grid ancillary services considering the uncertainties in plug-in electric vehicle availability and service/localization limitations in distribution grids. Appl. Energy 2016, 171, 523-540. [CrossRef]

46. e-sios. System Operator Information System. Available online: https://www.esios.ree.es/en/market-and-prices (accessed on 11 October 2021).

47. GAMS Development Corporation. GAMS—A User's Guide, GAMS Release 24.2.1; GAMS Development Corporation: Washington, DC, USA, 2013. 